\title{
Mitochondrial Factors and VACTERL Association-Related Congenital Malformations
}

\author{
S. Siebel B.D. Solomon
}

Medical Genetics Branch, National Human Genome Research Institute, National Institutes of Health, Bethesda, Md., USA

\begin{abstract}
Key Words
Congenital malformations $\cdot$ Inborn errors of metabolism . Mitochondrial dysfunction - Respiratory chain - VACTERL . VATER
\end{abstract}

\begin{abstract}
VACTERL/VATER association is a group of congenital malformations characterized by at least 3 of the following findings: vertebral defects, anal atresia, cardiac defects, tracheoesophageal fistula, renal anomalies, and limb abnormalities. To date, no unifying etiology for VACTERL/VATER association has been established, and there is strong evidence for causal heterogeneity. VACTERL/VATER association has many overlapping characteristics with other congenital disorders that involve multiple malformations. In addition to these other conditions, some of which have known molecular causes, certain aspects of VACTERL/VATER association have similarities with the manifestations of disorders caused by mitochondrial dysfunction. Mitochondrial dysfunction can result from a number of distinct causes and can clinically manifest in diverse presentations; accurate diagnosis can be challenging. Case reports of individuals with VACTERL association and confirmed mitochondrial dysfunction allude to the possibility of mitochondrial involvement in the pathogenesis of VACTERL/VATER association. Further, there is biological plausibility involving mitochondrial dysfunction as a possible etiology related to a diverse group of congenital malformations, including those seen in at least a subset of individuals with VACTERL association.

Copyright $\odot 2013$ S. Karger AG, Basel
\end{abstract}

Friedrich Nietzsche's observation that 'all that is profound loves the mask' holds true for many aspects of medical science, especially for certain relatively esoteric medical conditions. In this review, we hope to address potential connections between 2 disorders: VACTERL association and mitochondropathies. These disorders may be thought of as profound and 'masked' in terms of clinical and biological challenges related to understanding, diagnosing and managing these conditions. In order to describe this association and to allow this review article to be accessible and informative to a wide variety of clinicians and researchers, we will discuss the following topics: definitions of VATER/ VACTERL association; clinical and biological aspects of mitochondria in health and disease; case reports implicating mitochondrial dysfunction in VATER/ VACTERL association; potential extrapolations and links to other disorders.

\section{VATER/VACTERL Association}

VATER association was first defined in the early $1970 \mathrm{~s}$ by Quan and Smith [1972, 1973] to describe patients found to have a nonrandom association of congenital anomalies: vertebral defects, anal atresia, tracheo-esophageal fistula with esophageal atresia, radial and renal dysplasia. The acronym was later expanded to VACTERL to account for patients with additional congenital anomalies including cardiovascular and limb defects other than

\section{KARGER}

Fax +4161306 1234

E-Mail karger@karger.com

www.karger.com (c) 2013 S. Karger AG, Basel

$1661-8769 / 13 / 0042-0063 \$ 38.00 / 0$

Accessible online at:

www.karger.com/msy
Benjamin D. Solomon, MD

NIH, MSC 3717

Building 35, Room 1B-207

Bethesda, MD 20892 (USA)

E-Mail solomonb@mail.nih.gov 
radial dysplasia [Quan and Smith, 1972, 1973; Temtamy and Miller, 1974; Nora and Nora, 1975].

VACTERL association has an estimated frequency of approximately 1-9/100,000 infants [Khoury et al., 1983; Czeizel and Ludányi, 1985; Botto et al., 1997] and has no known ethnic or population-based predilection [Khoury et al., 1983; Czeizel and Ludányi , 1985; Weaver et al., 1986; Evans et al., 1992, 1999; Rittler et al., 1996; Botto et al., 1997; Källén et al., 2001; Seo et al., 2010; Solomon et al., 2010b, c; Wijers et al., 2010]. The estimated incidence is challenging due to variable diagnostic criteria, clinical heterogeneity [reviewed in Solomon, 2011] and the overlap with many other conditions [Evans et al., 1992, 1999; Rittler et al., 1996; Källén et al., 2001; Solomon et al., 2010b, c].

To date, no unifying or major etiology has been identified, and there is strong evidence for causal heterogeneity [Khoury et al., 1983; Evans et al., 1992, 1999; Solomon et al., 2010b, c]. Possible candidate genes have been reported in isolated reports, as have other factors, such as primary and secondary mitochondrial dysfunction and exposure to known teratogens, including gestational diabetes, maternal smoking, alcohol, and lead exposure in pregnancy [Nora et al., 1978; Czeizel and Ludányi, 1985; Levine and Muenke, 1991; Tüzel et al., 2007; Zhao et al., 2007; Castori et al., 2008; van Rooij et al., 2010; Wijers et al., 2010].

Mitochondrial dysfunction is an emerging area of interest as a plausible etiology of VACTERL association in at least a small proportion of affected individuals [Chan et al., 2002; Ornoy, 2007; Ornoy et al., 2010; Wang and Moley, 2010]. To date, 6 individuals with VACTERL association and demonstrated mitochondrial dysfunction have been described [Cormier-Daire et al., 1996; Damian et al., 1996; von Kleist-Retzow et al., 2003; Thauvin-Robinet et al., 2006; Solomon et al., 2011].

\section{Basic Mitochondrial Biology}

Mitochondria are ubiquitous, essential organelles of energy metabolism in nucleated mammalian cells. The number of mitochondria in a cell varies widely by organism and tissue type [Alberts et al., 1994; Voet et al., 2006]. A mitochondrion is composed of different compartments with individual functions (fig. 1). The inner mitochondrial membrane houses the oxidative phosphorylation (OXPHOS) system, which generates ATP, the major source of cellular energy. The mitochondrial matrix, enclosed by the inner membrane, contains enzymes involved in amino acid, carbohydrate, and lipid metabo- lism, mitochondrial ribosomes, and the mitochondrial genome [Alberts et al., 1994], the latter of which encodes key enzymes involved in energy metabolism. In addition to energy production, mitochondria play a central role in membrane potential regulation [Voet et al., 2006], apoptosis-programmed cell death [Green, 1998], calcium storage and signaling [Hajnóczky et al., 2006], and regulation of oxidative stress.

Of special interest in the context of VACTERL association is the OXPHOS system and the citric acid cycle (Krebs) cycle. The OXPHOS system refers to a multienzyme complex on the inner mitochondrial membrane consisting of NADH Coenzyme Q-reductase (complex I), succinate CoQ reductase (complex II), CoQ-H2 cytochrome reductase (complex IV), and ATP-synthase (complex V). Complexes I-IV constitute the respiratory chain system. The citric acid cycle cycle is located in the matrix; the initial rate limiting step is controlled via the multienzyme pyruvate dehydrogenase complex. There is evidence that citric acid cycle and/or pyruvate metabolism defects are causally involved in congenital anomalies (see below) [von Kleist-Retzow et al., 2003].

\section{Mitochondrial Genetics}

Mitochondria have their own unique genome; mitochondrial proteins may be encoded by nuclear or mitochondrial DNA (mtDNA) such that a mutation in either genome can lead to aberrant mitochondrial enzyme activity. Over 250 different mtDNA mutations have been reported in humans, and these mutations have been identified as disease-causing in approximately 1 in 5,000 overall individuals, with an incidence of pathogenic variants reported in 1 in 200 live births (however, it is important to note that the presence of a pathogenic variant will not necessarily lead to clinical manifestations) [Chinnery et al., 2000; Skladal et al., 2003; Elliott et al., 2008; Schaefer et al., 2008; Spinazzola, 2011].

Mammalian cells contain a varying but large number of mitochondria. As all mitochondria in the zygote are derived from the oocyte (with rare exceptions reported), mtDNA mutations can only be transmitted from a female carrier to her offspring [Schwartz and Vissing, 2002]. Conversely, conditions resulting from mutations of nuclear DNA follow Mendelian inheritance patterns (e.g. autosomal recessive).

In healthy tissue, all cells theoretically receive identical (wild type) mtDNA from their parental cell, which is referred to as homoplasmy. However, in the case of an 
Fig. 1. Overview of mitochondrial location and anatomy, showing a human cell containing multiple mitochondria, as well as the respiratory chain complexes. Many mitochondrial proteins are encoded by nuclear DNA and transported into the mitochondria by specialized transport systems (arrow). Multiple mtDNA molecules are located within the mitochondrial matrix. Each mtDNA molecule encodes 37 proteins, of which 13 are part of the respiratory chain. The respiratory chain, shown in more detail in the bottom portion of the figure, is located on the inner mitochondrial membrane, and consists of 5 different complexes. Within the mitochondrial matrix, pyruvate enters the tricyclic acid cycle, which is linked with the respiratory chain through complex II. Except for complex II, all complexes of the respiratory chain are encoded by both nuclear and mtDNA.

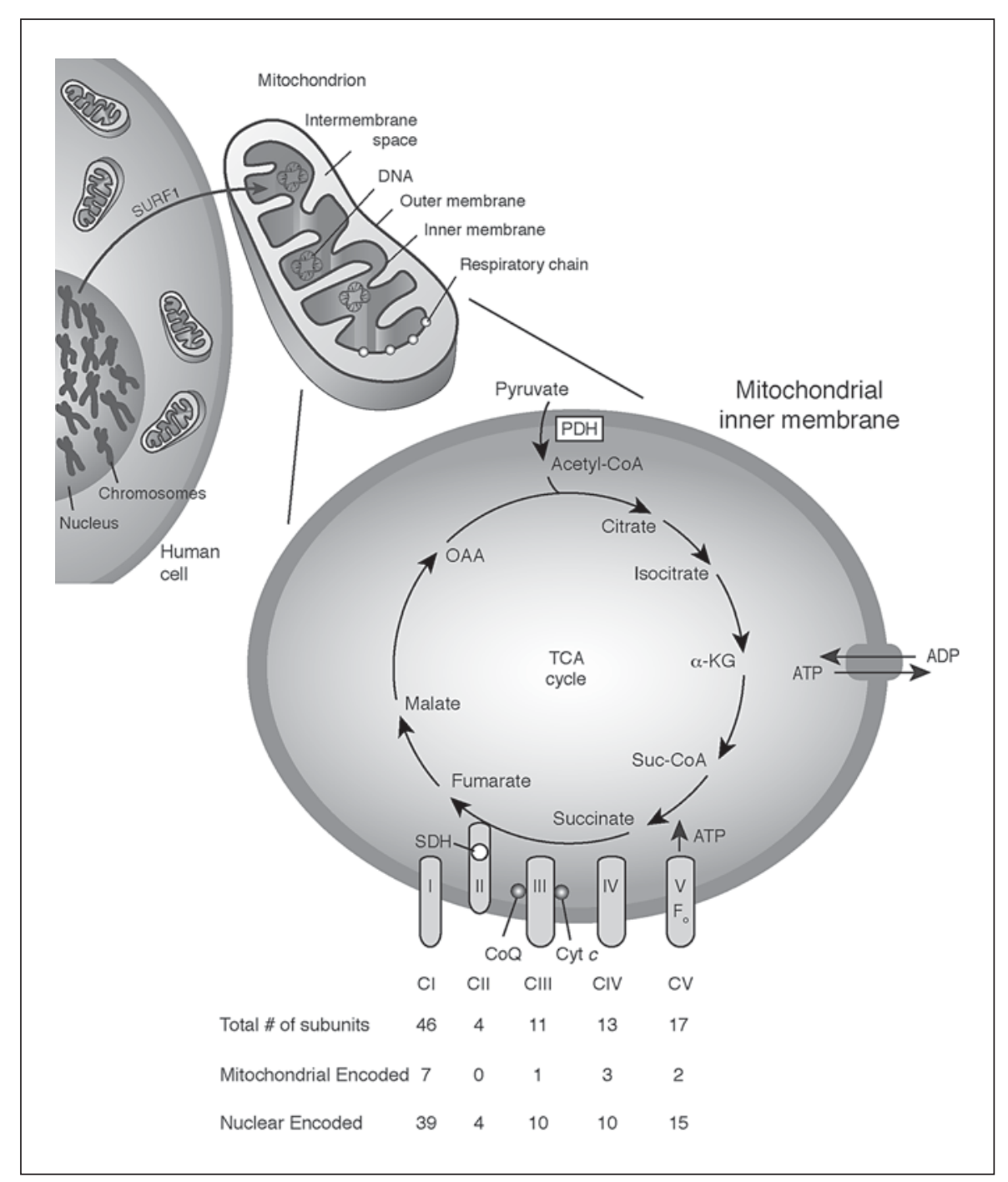

mtDNA mutation, not all offspring cells receive an equal amount of mutated mtDNA (fig. 2). During cell division, wildtype and mutant mtDNA from parental cells are distributed randomly among daughter cells. Tissues that consist of cells that carry both mutated and wildtype mtDNA are in a state referred to as heteroplasmy. The degree of heteroplasmy influences tissue function, and once the mutant load passes a certain threshold, tissue function may become compromised. This so called 'threshold effect' varies in different tissue types, with a lower threshold for disease expression in tissues with higher energy demands, such as the central nervous system, skeletal and cardiac muscle, pancreatic islets, liver, and kidney [Boulet et al., 1992; Spinazzola, 2011]. This helps explain the common pattern of clinical manifesta- tions in mitochondrial disease [White et al., 1999; Thorburn and Dahl, 2001; Wallace, 2001].

Mitochondrial dysfunction can manifest in many organ systems and can be challenging to diagnose. We will outline key tests here, (as well as examples of how these tests may also show the presence of certain 'classic' biochemical disorders) though this brief overview is not intended to be comprehensive.

The initial laboratory evaluation in suspected mitochondrial disease may include pyruvate and lactate levels, as well as lactate/pyruvate ratio, blood urea nitrogen, glucose, plasma amino acids, urine organic acids, ammonia levels, serum electrolytes with anion gap, and acylcarnitine profile with total and free carnitine levels. Elevated lactate with a lactate/pyruvate ratio of 10-20 may indicate 
Fig. 2. Key features and concepts involved in mitochondrial inheritance. A maternal cell may be heteroplasmic for mutant mtDNA and wildtype mtDNA. During mitotic segregation, mutant and wildtype mtDNA are distributed randomly among the daughter cells, resulting in a distribution of the degree of heteroplasmy in daughter cells. Selective mtDNA replication and amplification further increases the level of heteroplasmy in mature oocytes. As only oocytes contribute mitochondria to the zygote, the level of mutant mtDNA depends on the mtDNA mutant load inherited from the mother. If the mutant load remains below a tissue-specific threshold, the offspring may not demonstrate a detectable disease phenotype. However, depending on the proportion of mutant mtDNA, the offspring may show a variable phenotype, with the severity of manifestations as least partially related to the mutant load.

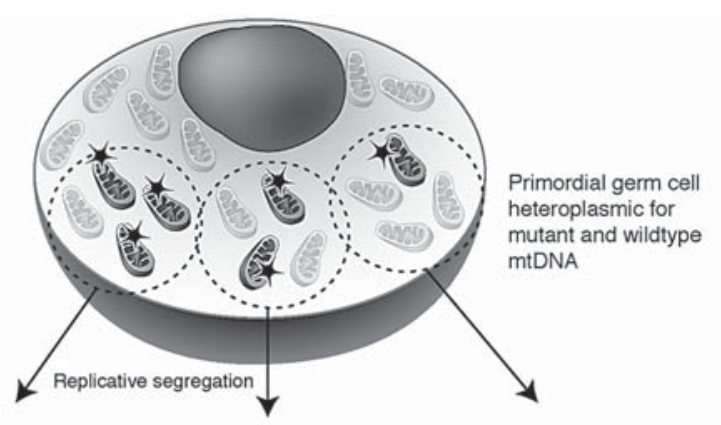

Small number of mother's mitochondria, selected randomly, goes into each primary oocyte "Bottleneck Effect"
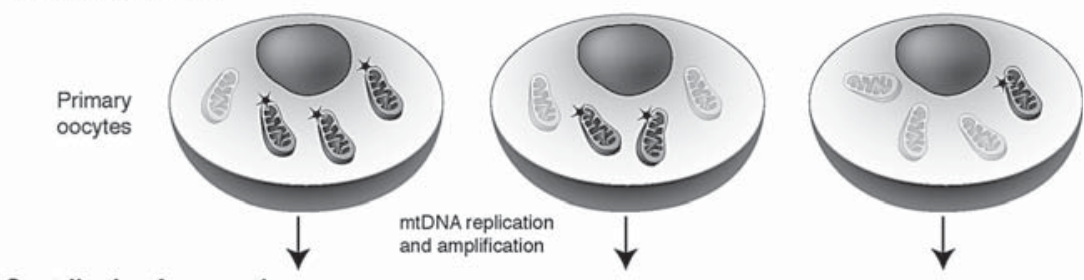

Contribution from mother
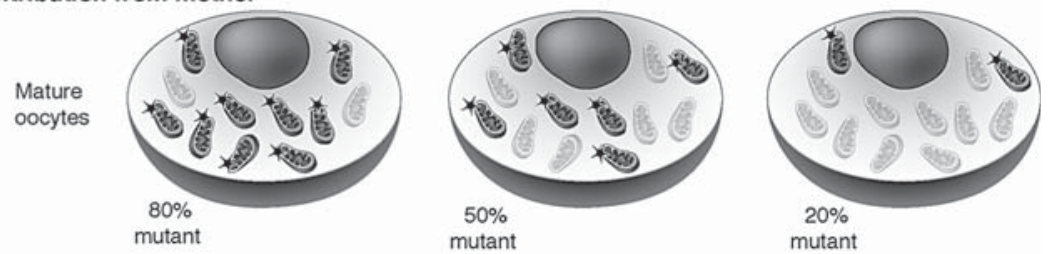

Contribution from father

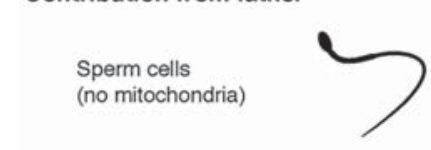

Possible outcome

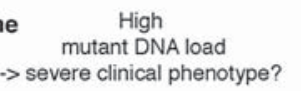

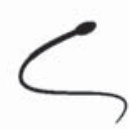

Moderate mutant DNA load $\rightarrow$ mild clinical phenotype?

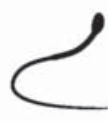

Low

mutant DNA load (below threshold) $\rightarrow$ no clinical phenotype? a disorder of pyruvate metabolism, such as can occur in PDH deficiency; an elevated lactate level with a lactate/ pyruvate ratio $>20$ may indicate an OXPHOS disorder. Low blood urea nitrogen and high ammonia levels can be found in urea cycle defects. Abnormal blood glucose and ketone levels in addition to specific acylcarnitine, plasma amino acid and urine organic acid profiles can point to specific fatty acid oxidation defects, aminoacidopathies and organic acidurias, respectively. Skin or muscle biopsies can be used for histological (such as electron microscopy) or biochemical studies of mitochondria. Histochemical studies are helpful to evaluate the respiratory chain function, and genetic testing can help identify mtDNA or nuclear DNA mutations. For more details about testing for mitochondrial disorders, please refer to the review by Debray et al. [2008].

\section{VACTERL Association and Mitochondrial Dysfunction: Possibly Commonalities}

There are interesting overlaps between VACTERL association and mitochondrial disease. Clinically, both share involvement of multiple disparate organs, high variability of disease expression (even within families with multiple affected individuals) and apparently multiple modes of inheritance. There are several reports of individuals with VACTERL association who developed manifestations consistent with mitochondrial dysfunction (though not all reported instances have been proven to involve mitochondrial dysfunction) [Solomon et al., 2010b, c; Solomon, 2011]. Though it would likely be an oversimplification to posit that mitochondrial dysfunction plays a frequent direct causative role in VACTERL 
Table 1. Summary of clinical findings in individuals with VACTERL association and strong evidence for mitochondrial disease

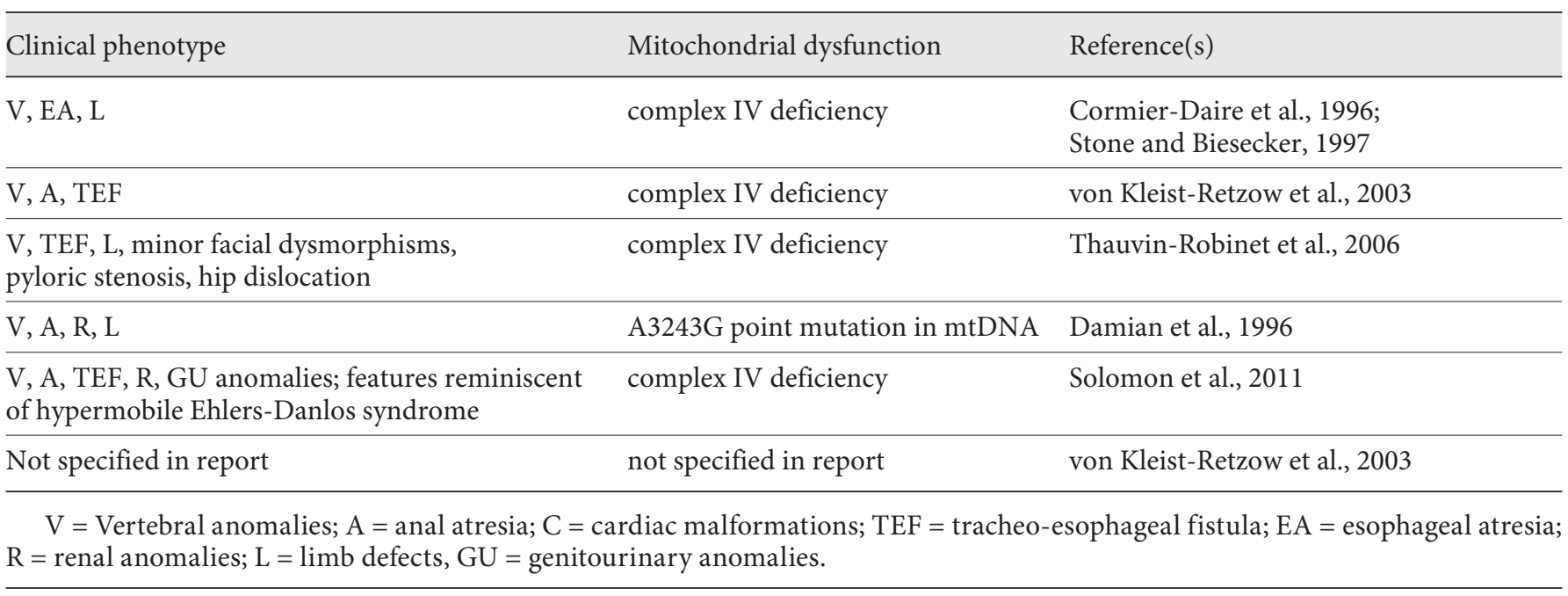

association, links between the 2 classes of disorders remain interesting. For example, defective mitochondria, randomly distributed to different organ systems, may help explain why disparate tissues are affected in some instances of VACTERL association, and varying levels of heteroplasmy may explain the broad spectrum of disease seen in both sporadically affected individuals as well as kindreds with multiple affected members [Solomon et al., $2010 \mathrm{~b}, \mathrm{c}]$. Further, as described below, there is a strong biological argument by which mitochondrial dysfunction could plausibly result in the pattern of congenital anomalies seen in VACTERL association.

\section{VACTERL Association and Mitochondrial Dysfunction: Reported Cases}

VACTERL association and mitochondrial disorders have been largely regarded as 2 distinct medical entities. Classically, VACTERL association was categorized as related to inborn errors of development, whereas mitochondropathies are typically grouped within or alongside the inborn errors of metabolism (IEM). However, there are a small number of case reports of individuals with both VACTERL association and mitochondrial dysfunction.

In summary, to date, 6 cases of proven mitochondrial dysfunction in patients with VACTERL association have been described in the literature [reviewed in Solomon et al., 2011]. Interestingly, 5 of the 6 affected individuals demonstrated complex IV deficiencies [Solomon et al., 2011], whereas one individual had an np 3243 A $>$ G mitochondrial DNA point mutation. This latter patient presented with mitochondrial encephalopathy, lactic acidosis and stroke (MELAS-syndrome) [Damian et al., 1996]. All described individuals presented with features of VACTERL association as well as occasional additional minor anomalies not classically described as part of VACTERL association, such as facial dysmorphisms, pyloric stenosis and hypermobility [Solomon et al., 2011]. Overall, 5 of the 6 individuals presented with vertebral anomalies; 3 had anal atresia; 4 showed esophageal involvement; 2 had limb anomalies; 1 had renal anomalies; and 2 patients presented with additional minor dysmorphic features.

Multiple additional individuals with VACTERL association and strong clinical evidence of mitochondrial dysfunction have been reported - these individuals were initially described as having VACTERL association and later demonstrated features commonly seen in mitochondrial disorders, including characteristic patterns of cardiac, neurologic, gastrointestinal, and endocrine dysfunction. However, due to the frequent need of invasive testing and the diagnostic difficulties involved in proving mitochondrial disease, it is important to note that not all of these latter individuals had proven mitochondrial dysfunction, and thus, the connection may be spurious in some instances [Solomon et al., 2011] (table 1). 


\section{Further Extrapolations: The Role of Mitochondria in Embryonic Development and Human Disease}

As mitochondria provide the major source of energy (the OXPHOS system is the major source of energy, in the form of ATP; importantly, this system also produces reactive oxygen species/free radicals) for most mammalian cellular processes, including embryogenesis, it is unsurprising that primary and secondary mitochondrial dysfunction can have a significant impact on human development [Lemasters et al., 1999]. First, embryogenesis is an energy-dependent process, and ATP availability is necessary for normal tissue development and organization [Stone and Biesecker, 1997; von Kleist-Retzow et al., 2003]. Animal models show that the period of embryogenesis is particularly vulnerable to mitochondrial dysfunction due to high energy demands as well as related results of aberrant mitochondrial function (see below) [Saijo et al., 1997; Li et al., 2000; Johnson et al., 2001; Dumollard et al., 2007]. Thus, a lack of necessary energy (e.g. due to respiratory chain disease or mutations of pyruvate dehydrogenase-, cytochrome c-, or dihydrolipoamide dehydrogenase-encoding genes) may be detrimental to the developing embryo and lead to congenital anomalies [Saijo et al., 1997; Li et al., 2000; Johnson et al., 2001].

Second, under normal conditions, the respiratory chain generates approximately $2 \%$ of free radicals from its electrons. This percentage increases when electron transfer becomes dysfunctional. Free radicals/reactive oxygen species can cause oxidative damage (to both cells and genetic material); once innate antioxidant defense mechanisms are overwhelmed, this can result in apoptotic or necrotic cell death [Kroemer and Reed, 2000; Kowaltowski et al., 2009], leading to abnormal embryonic development and the clinical expression of congenital malformations [Van Blerkom, 2009]. Related to this, aberrant or dysregulated apoptosis induced by dysfunctional mitochondria may further trigger the apoptosis of surrounding cells (this phenomenon is commonly known as the bystander effect), further interfering with normal development. Additionally, the resulting malformations may involve a vicious cycle in which mitochondrial dysfunction begets oxidative stress, causing damage to the same respiratory chain deficient cells that show increased vulnerability to the same oxidative stress for which they are responsible [Yanicostas et al., 2011].

Relevant developmental malformations have been described in several animal studies. An antisense morpholino zebrafish model for the surf1, coxaa, and coxab genes (encoding the cytochrome $\mathrm{c}$ oxidase enzyme subunits)

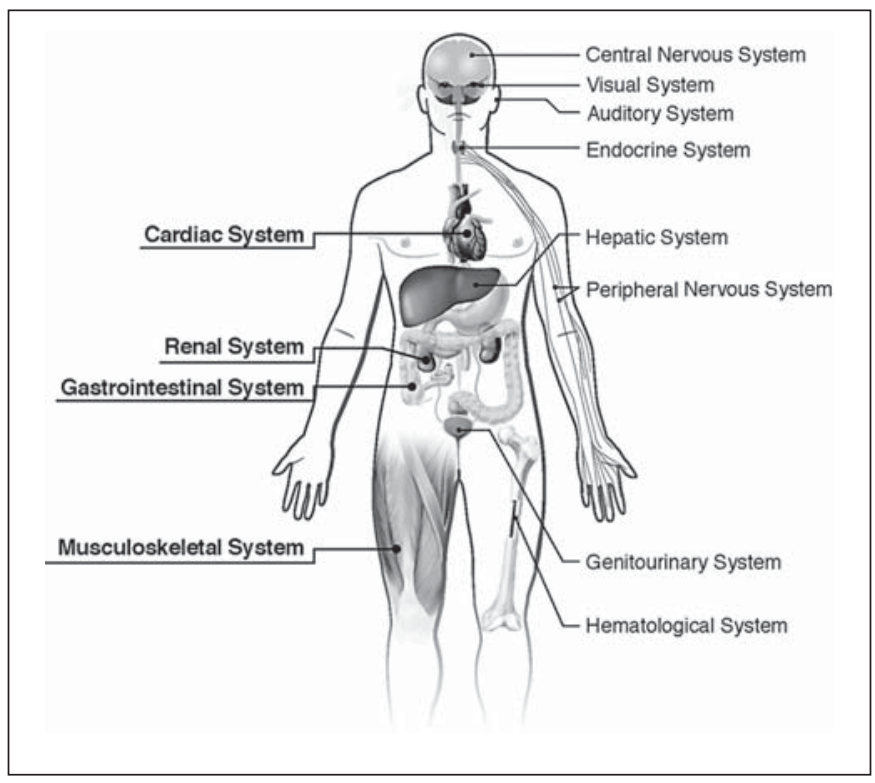

Fig. 3. Involvement of multiple organ systems in mitochondrial disorders as well as related inborn errors of metabolism. Organ systems underlined/in bold indicate those in which there is most frequently a clinical overlap between individuals with VACTERL association and mitochondrial disorders/related IEM.

has a consistent phenotype that includes structural malformations. In this model, apoptosis is dramatically higher in tissues in which malformations occur, whereas the effects on other tissues (such as the heart) seem to be more related to energy deficiency [Baden et al., 2007].

In human studies, one case series described congenital anomalies in patients with confirmed mitochondrial dysfunction secondary to respiratory chain disease/ OXPHOS dysfunction; these patients demonstrated a wide spectrum of malformations involving multiple unrelated organ systems. Reported malformations included dysmorphic craniofacial features, cardiac malformations, limb anomalies, genitourinary anomalies, and gastrointestinal malformations [von Kleist-Retzow et al., 2003] (table 2 and fig. 3).

\section{Further Connections with Inborn Errors of Metabolism}

To extend the discussion further to other biologically related disorders, it is important to point out that normal mitochondrial function involves more than the respiratory chain mechanism: the mitochondria house a variety of enzymes involved in the metabolism of amino acids, 
Table 2. Summary of antenatal/postnatal manifestations of mitochondrial respiratory chain deficiencies in case series and single case report

\begin{tabular}{|c|c|c|}
\hline Clinical manifestation & $\begin{array}{l}\text { Proportion } \\
\text { affected }^{*}\end{array}$ & $\begin{array}{l}\text { Respiratory chain } \\
\text { deficiencies in } \\
\text { individuals with } \\
\text { described } \\
\text { manifestations }\end{array}$ \\
\hline \multicolumn{3}{|l|}{ Central nervous system } \\
\hline Corpus callosum agenesis & 1 in 300 & C I, IV \\
\hline Dandy-Walker malformation & 1 in 300 & C II \\
\hline Porencephalic cysts/enlarged ventricles & 1 in 300 & C I \\
\hline \multicolumn{3}{|l|}{ Cardiac system } \\
\hline VSD & 1 in 300 & C II \\
\hline Hypertrophic cardiomyopathy & 4 in 300 & C I, II, V \\
\hline Cardiac rhythm anomalies & 4 in 300 & C I, II, IV \\
\hline \multicolumn{3}{|l|}{ Gastrointestinal system } \\
\hline $\begin{array}{l}\text { Complex malformation with duodenal } \\
\text { atresia, duplication of the ductus }\end{array}$ & & \\
\hline \multicolumn{3}{|c|}{ Renal system } \\
\hline Hydronephrosis & 3 in 300 & C I, IV \\
\hline \multicolumn{3}{|l|}{ Miscellaneous/other } \\
\hline Isolated growth retardation & 48 in 300 & C I, IV, V \\
\hline Polyhydramnios & 6 in 300 & C I, IV \\
\hline Oligohydramnios & 2 in 300 & C III \\
\hline Arthrogryposis & 1 in 300 & $\mathrm{CV}$ \\
\hline Decreased fetal movement & 1 in 300 & N/A \\
\hline VACTERL & 2 in 300 & C IV \\
\hline
\end{tabular}

* Proportion affected is derived from the case series described in von Kleist-Retzow et al. [2003]. C = Complex; N/A = not applicable.

References: Cormier-Daire et al., 1996; Stone and Biesecker, 1997; von Kleist-Retzow et al., 2003; Thauvin-Robinet et al., 2006; Solomon et al., 2011.

carbohydrates and lipids. Certain IEM can be caused by deficient activity of enzymes related to these metabolic pathways, such as in mitochondrial fatty acid oxidation disorders, urea cycle disorders, amino acid metabolism defects resulting in organic aciduria, pyruvate metabolism disorders, and tricarboxylic acid cycle disorders. Mitochondrial dysfunction secondary to toxic metabolite accumulation is a key feature of another group of IEM, namely organic acidurias (e.g. fumaric aciduria, 3-methylglutaconic aciduria and glutaric aciduria). Organic acidurias are caused by deficient enzyme function in the metabolism of coenzyme A activated carboxylic acids. These carboxylic acids are mainly derived from amino acid catabolism but can also come from defective mitochondrial lipid metabolism or as products of the tricarboxylic acid cycle [Goodman, 1980; Goodman and Markey, 1981; Chalmers and Lawson, 1982; Scriver et al., 2001; Wajner and Goodman, 2011].
Endogenous organic acid accumulation can perturb mitochondrial homeostasis by directly inhibiting OXPHOS consequent energy production [CheemaDhadli et al., 1975; Gregersen, 1981; Evangeliou et al., 1985; Massoud and Leonard, 1993; Okun et al., 2002; Baumgartner et al., 2007] or indirectly, via decreased expression of mtDNA of the electron transfer complexes IIV [Mardach et al., 2005; Schwab et al., 2006; Sperl et al., 2006; de Keyzer et al., 2009]. Further, abnormal mitochondrial structure has also been observed, especially in the skeletal muscle, heart and liver in patients with organic acidurias [Mardach et al., 2005; Schwab et al., 2006; de Keyzer et al., 2009; Wortmann et al., 2009].

Patients affected with these IEM frequently present with neurologic manifestations, sometimes accompanied by additional findings more commonly associated with conditions involving structural malformations, the underlying pathogenesis of which is incompletely understood. However, growing evidence has emerged indicating that mitochondrial dysfunction is directly or indirectly involved in clinical manifestations such as the congenital malformations that are reported in some individuals with IEM. A key question relates to the relative paucity of congenital malformations in patients with IEM, begging the question whether such co-occurences may be largely coincidental. One explanation why less IEM present with congenital malformations may involve the fact that most IEM are compensated for in utero by maternal/placental metabolism. According to this type of explanation, most toxic metabolites may be eliminated from fetal/embryonic circulation, delaying clinical manifestations until the postnatal period. Thus, the negative effects of IEM on embryogenesis may not affect mitochondrial dysfunction directly. On the other hand, clinical manifestations of mitochondrial dysfunction (in the form of structural malformations) due to direct deficient enzyme activity of the respiratory chain may, in rare instances, be more severe and may be detected even during the antenatal period [Nissenkorn et al., 2001; von Kleist-Retzow et al., 2003; Solomon et al., 2011].

To focus further on a few specific examples, congenital anomalies are frequently described in PDHc deficiency [Brown, 2005], glutaric aciduria type 2 and 3-methylglutaconic aciduria type IV [Goodman et al., 1983], pyruvate oxidase deficiency [Damian et al., 1996], and fumaric aciduria [Kerrigan et al., 2000; Shih and Mandell, 2006]. The spectrum of described anomalies is broad. Common features involve structural central nervous system (CNS) anomalies, including dysgenesis of the corpus callosum, 
Table 3a. Teratogens reported as associated with VACTERL/ VATER association

\begin{tabular}{ll}
\hline $\begin{array}{l}\text { Teratogens associated with } \\
\text { VACTERL/VATER association }\end{array}$ & References \\
\hline Lead & Levine and Muenke, 1991 \\
Lovastatin & Ghidini et al., 1992 \\
Dibenzepin & Merlob and Naor, 1994 \\
Maternal diabetes & Loffredo et al., 2001 \\
Exogenous sex hormones & Kaufman, 1973; Nora and Nora, \\
& 1975; Nora et al., 1978; \\
& Lammer et al., 1986 \\
\hline
\end{tabular}

Table 3b. Teratogens reported as associated with mitochondrial dysfunction

\begin{tabular}{ll}
\hline $\begin{array}{l}\text { Teratogens associated with } \\
\text { mitochondrial dysfunction }\end{array}$ & References \\
\hline $\begin{array}{l}\text { Lead } \\
\text { Ethanol }\end{array}$ & Wang et al., 2009 \\
$\begin{array}{l}\text { Glycosides } \\
\text { Polybrominated diphenyl ethers } \\
\text { Nucleoside analogues reverse } \\
\quad \text { transcriptase inhibitors }\end{array}$ & $\begin{array}{l}\text { Marx et al., 2006 } \\
\text { Maternal diabetes }\end{array}$ \\
\end{tabular}

polymicrogyria and pachygyria, and additional white matter dysplasia. Dysmorphic facial features observed in conjunction with CNS malformations have been described as bearing some resemblance to fetal alcohol syndrome, which can include a long philtrum, epicanthal folds and a short nose with anteverted nares as well as additional features such as frontal bossing and upslanting palpebral fissures [Saijo et al., 1997; Cormier-Daire et al., 1996; Nissenkorn et al., 2001; Brown, 2005; Shih and Mandell, 2006]. In individuals with mitochondrial dysfunction, Cormier-Daire et al. [1996] reported craniofacial anomalies, including round face, high forehead, flat philtrum, epicanthal folds, low-set ears, short neck, and ear dysplasia suggestive of the features seen in individuals with CHARGE syndrome as well as the structural malformations described above affecting the limbs, gastrointestinal, genitourinary, and cardiac systems [CormierDaire et al., 1996]. Additional anomalies reported in individuals with IEM include genitourinary anomalies, inguinal and umbilical hernia, and brachydactyly as well as a spectrum of end-organ damage affecting multiple tissues (including the brain, liver and heart) [Goodman et al., 1983; Cormier-Daire et al., 1996; Saijo at al., 1997; Li et al., 2000; Johnson et al., 2001; Nissenkorn et al., 2001; Rudolph et al., 2002; De Meirleir, 2005; Shih and Mandell, 2006; Wajner and Goodman, 2011].

\section{The Contribution of Teratogens}

Teratogens have long been known to have a major impact on embryonic development, and a group of agents, including lead [Levine and Muenke, 1991; Wang et al., 2009], glycosides [Marx et al., 2006], ethanol [Henderson et al., 1999], and maternal diabetes [Loffredo et al., 2001], have been reported as being associated with VACTERL association and are additionally known to impair mitochondrial function. This impairment of mitochondrial function can involve alterations of mitochondrial ultrastructure, interfering with respiratory chain function and exacerbating oxidative stress through increased production of free radicals. Oxidative stress may cause damage to many organs, including the heart, lung, liver, kidneys, reproductive organs, and CNS [Ahamed and Siddiqui, 2007] (table 3a, b).

This putative link between VACTERL association, teratogens and mitochondrial dysfunction raises the question whether early prenatal exposure to certain teratogens induces mitochondrial dysfunction or at least exacerbates preexisting mitochondrial dysfunction in heteroplasmic tissues, where the proportion of dysfunctional mitochondria is initially below the threshold. Teratogens may act as an additional stressor on the already vulnerable heteroplasmic tissues, thereby rendering more mitochondria dysfunctional. In this 'susceptibility model', a combination of factors would ultimately cause the overall proportion of impaired mitochondria supercede tissue-specific functional thresholds.

\section{Discussion}

VACTERL association is a clinically and causally heterogenous disorder, and the overall mechanism of disease remains incompletely understood. The involvement of many apparently unrelated organ systems, as well as the lack of a definite Mendelian inheritance mode in the majority of instances, suggests the presence of new, currently unidentified mutations in some individuals, as well as the possibility of a more complex multifactorial disorder in other individuals, with genetic, epigenetic, environ- 
mental, and more purely stochastic factors combinatorially involved in disease pathogenesis.

To date, no common causal link between mitochondrial dysfunction and the development of VACTERL association has been demonstrated. Mitochondrial dysfunction might not be the sole cause for the vast majority of individuals with VACTERL association, but could play a role through increasing tissue susceptibility to aberrant development. Additionally, the recognition of the involvement of mitochondrial dysfunction in the development of congenital anomalies through impaired energy production, reactive oxygen species generation and aberrant apoptosis in well-established disorders opens the door for further discussion, investigation and research in the fast developing field of complex disorders, including explanations of variable disease expression in some Mendelian conditions. For example, even in well-described genetic disorders, such as Down syndrome, which can include multiple congenital anomalies of the cardiac, central nervous and gastrointestinal systems [Solomon et al., 2010a], mitochondropathies have been posited as disease modifier. Mitochondrial dysfunction due to mtDNA mutations, mitochondrial enzyme deficiencies leading to altered patterns of apoptosis and increased oxidative stress, has been reported as playing a role in the clinical manifestations of Down syndrome [Busciglio et al., 2002; Busciglio, 2010; Tiano and Busciglio, 2011], for example, by affecting the frequency of diabetes mellitus and Alzheimer disease, altering the immune system, and contributing to neurological effects [Prince et al., 1994; Bersu et al., 1998; Druzhyna et al., 1998; Schuchmann and Heinemann, 2000; Conti et al., 2007; Roat et al., 2007].

In summary, we suggest that mitochondrial dysfunction should be considered when a patient presents with multiple congenital anomalies and clinical signs, and symptoms of mitochondrial involvement or related IEM. These clinical clues can include evidence for a maternal inheritance pattern, abnormal glycemic control, cyclic vomiting, developmental delay and other related signs of neurological disease, dysautonomia, intestinal malabsorption, pancreatic insufficiency, ptosis, episodic vomiting, and clinical response to 'mitochondrial cocktail' [Solomon et al., 2011].

Finally, it must be admitted that past critiques have pointed out that mitochondrial defects have been the default explanation for many inexplicable conditions. Others believe that mitochondria may, however, play a unifying role in a large and underappreciated number of medically significant conditions. DiMauro [2001] has even called mitochondrial mutations a 'Pandora's box', per- haps reminding us of the difficulties in understanding and interpreting the many types of mitochondrial dysfunction and their potentially devastating consequences. At the same time, we must stride for means to discover new and better treatments for the many manifestations of mitochondrial disease. Despite the diversity of opinions, the bottom line is that much more research and critical evaluation is required in order to find answers for individuals affected by either or both VACTERL association and mitochondrial disease. This is especially important as some metabolic and mitochondrial disorders are amenable to certain types of treatment, and key avenues may emerge in the study of VACTERL association and related conditions related to mechanisms to ameliorate disease severity. As the causes of VACTERL association are discovered, it will be fascinating to look back in order to determine whether identified molecular etiologies do need point to a common path involving the mitochondria.

\section{Acknowledgements}

This research was supported by the Division of Intramural Research, National Human Genome Research Institute (NHGRI), National Institutes of Health and Human Services, USA. B.D.S. would like to thank Max Muenke, MD, for his support and mentorship. The authors would like to thank Lynne Wolfe, MS, CRNP, for her helpful insights and discussion, and Julia Fekecs and Darryl Leja for their expert illustrations, and are extremely grateful to the patients and families who participate in our studies.

\footnotetext{
References Ahamed M, Siddiqui MK: Low level lead exposure and oxidative stress: current opinions. Clin Chim Acta 383:57-64 (2007).

Alberts B, Johnson A, Lewis J, Raff M, Roberts K, Walter P: Molecular Biology of the Cell (Garland Publishing Inc., New York 1994).

- Baden KN, Murray J, Capaldi RA, Guillemin K: Early developmental pathology due to cytochrome $\mathrm{c}$ oxidase deficiency is revealed by a new zebrafish model. J Biol Chem 282: 34839-34849 (2007).

- Baumgartner D, Scholl-Bürgi S, Sass JO, Sperl W, Schweigmann U, et al: Prolonged QTc intervals and decreased left ventricular contractility in patients with propionic acidemia. J Pediatr 150:192-197 (2007).

- Bersu ET, Ahmad FJ, Schwei MJ, Baas PW: Cytoplasmic abnormalities in cultured cerebellar neurons from the trisomy 16 mouse. Brain Res Dev Brain Res 109: 115-120 (1998).
} 
Blanche S, Tardieu M, Rustin P, Slama A, Barret $B$, et al: Persistent mitochondrial dysfunction and perinatal exposure to antiretroviral nucleoside analogues. Lancet 354:1084-1089 (1999).

Botto LD, Khoury MJ, Mastroiacovo P, Castilla EE, Moore CA, et al: The spectrum of congenital anomalies of the VATER association: an international study. Am J Med Genet 71: 8-15 (1997).

Brown GK: Congenital brain malformations in mitochondrial disease. J Inherit Metab Dis 28:393-401 (2005).

Boulet L, Karpati G, Shoubridge EA: Distribution and threshold expression of the transRNA(Lys) mutation in skeletal muscle of patients with myoclonic epilepsy and raggedred fibers (MERRF). Am J Hum Genet 51: 118-1200 (1992).

Busciglio J: The role of oxidative stress and mitochondrial dysfunction in Down's syndrome. Sixth Conference of the International Coenzyme Q10 Association, Brussels, May 2010.

- Busciglio J, Pelsman A, Wong C, Pigino G, Yuan $\mathrm{M}$, et al: Altered metabolism of the amyloid beta precursor protein is associated with $\mathrm{mi}-$ tochondrial dysfunction in Down's syndrome. Neuron 33:677-688 (2002).

-Castori M, Rinaldi R, Capocaccia P, Roggini M, Grammatico P: VACTERL association and maternal diabetes: a possible causal relationship? Birth Defects Res A Clin Mol Teratol 82:169-172 (2008).

Chalmers RA, Lawson AM: Organic acids in man. Analytical chemistry, biochemistry and diagnosis of the organic acidurias, ed 1 (Chapman and Hall, London 1982)

-Chan BW, Chan KS, Koide T, Yeung SM, Leung $\mathrm{MB}$, et al: Maternal diabetes increases the risk of caudal regression caused by retinoic acid. Diabetes 51:2811-2816 (2002).

-Cheema-Dhadli S, Leznoff CC, Halperin ML: Effect of 2-methylcitrate on citrate metabolism: implications for the management of patients with propionic acidemia and methylmalonic aciduria. Pediatr Res 9:905-908 (1975).

-Chinnery PF, Johnson MA, Wardell TM: The epidemiology of pathogenic mitochondrial DNA mutations. Ann Neurol 48:188-193 (2000).

Conti A, Fabbrini F, D’Agostino P, Negri R, Greco D, et al: Altered expression of mitochondrial and extracellular matrix genes in the heart of human fetuses with chromosome 21 trisomy. BMC Genomics 8:268 (2007).

-Cormier-Daire V, Rustin P, Rötig A, Chrétien D, Le Merrer M, et al: Craniofacial anomalies and malformations in respiratory chain deficiency. Am J Med Genet 66:457-463 (1996).

-Czeizel A, Ludányi I: An aetiological study of the VACTERL-association. Eur J Pediatr 144: 331-337 (1985).

-Damian MS, Seibel P, Schachenmayr W, Reichmann H, Dorndorf W: VACTERL with the mitochondrial NP 3243 point mutation. Am J Med Genet 62:398-403 (1996).
De Meirleir L: Inborn Errors of Metabolism, in Maria BL (ed): Current Management in Child Neurology, chapter 49, ed 3 (BC Decker Inc Hamilton, Ontario 2005)

- Debray FG, Lamberta M, Mitchell GA: Disorders of mitochondrial function. Curr Opin Pediatr 20:471-482 (2008).

de Keyzer Y, Valayannopoulos V, Benoist JF, Batteux F, Lacaille F, et al: Multiple OXPHOS deficiency in the liver, kidney, heart, and skeletal muscle of patients with methylmalonic aciduria and propionic aciduria. Pediatr Res 66:91-95 (2009).

DiMauro S, Schon EA: Mitochondrial DNA mutations in human disease. Am J Med Genet 106:18-26 (2001).

-Druzhyna N, Nair RG, LeDoux SP, Wilson GL: Defective repair of oxidative damage in $\mathrm{mi}$ tochondrial DNA in Down's syndrome. $\mathrm{Mu}$ tat Res 409:81-89 (1998).

Dumollard R, Duchen M, Carroll J: The role of mitochondrial function in the oocyte and embryo. Curr Top Dev Biol 77:21-49 (2007).

-Elliott HR, Samuels DC, Eden JA, Relton CL, Chinnery PF: Pathogenic mitochondrial DNA mutations are common in the general population. Am J Hum Genet 83:254-260 (2008).

Evangeliou A, Stumpf DA, Parks JK: Citrate synthase inhibition by acyl coenzyme A esters. Ann Neurol 18:383-384 (1985).

Evans JA, Vitez M, Czeizel A: Patterns of acrorenal malformation associations. Am J Med Genet 44:413-419 (1992).

-Evans JA, Greenberg CR, Erdile L: Tracheal agenesis revisited: analysis of associated anomalies. Am J Med Genet 82:415-422 (1999).

Ghidini A, Sicherer S, Willner J: Congenital abnormalities (VATER) in a baby born to mother using lovastatine. Lancet 339:14161417 (1992).

Goodman SI: An introduction to gas chromatography-mass spectrometry and the inherited organic acidemias. Am J Hum Genet 32 : 781-792 (1980).

Goodman SI, Markey SP: Diagnosis of organic acidemias by gas chromatography-mass spectrometry. Lab Res Methods Biol Med 6: 1-158 (1981).

Goodman SI, Reale M, Berlow S: Glutaric acidemia type II: a form with deleterious intrauterine effects. J Pediatr 102:411-413 (1983).

Green DR: Apoptotic pathways: the roads to ruin. Cell 94:695-698 (1998).

Gregersen N: The specific inhibition of the pyruvate dehydrogenase complex from pig kidney by propionyl-CoA and isovaleryl-Co-A. Biochem Med 26:20-27 (1981).

- Hajnóczky G, Csordás G, Das S, Garcia-Perez C, Saotome M, et al: Mitochondrial calcium signalling and cell death: approaches for assessing the role of mitochondrial $\mathrm{Ca} 2+$ uptake in apoptosis. Cell Calcium 40:553-560 (2006).

Henderson GI, Chen JJ, Schenker S: Ethanol, oxidative stress, reactive aldehydes, and the fetus. Front Biosci 4:D541-550 (1999).
Johnson MT, Mahmood S, Hyatt SL, Yang HS, Soloway PD, et al: Inactivation of the murine pyruvate dehydrogenase (Pdha1) gene and its effect on early embryonic development. Mol Genet Metab 74:293-302 (2001).

Källén K, Mastroiacovo P, Castilla EE, Robert E, Källén B: VATER non-random association of congenital malformations: study based on data from four malformation registers. Am J Med Genet 101:26-32 (2001).

Kaufman RL: Birth defects and oral contraceptives. Lancet 1:1396 (1973).

-Kerrigan JF, Aleck KA, Tarby TJ, Bird CR, Heidenreich RA: Fumaric aciduria: clinical and imaging features. Ann Neurol 47:583588 (2000)

Khoury MJ, Cordero JF, Greenberg F, James LM, Erickson JD: A population study of the VACTERL association: evidence for its etiologic heterogeneity. Pediatrics 71:815-820 (1983).

Kowaltowski AJ, de Souza-Pinto NC, Castilho RF, Vercesi AE: Mitochondria and reactive oxygen species. Free Radic Biol Med 47:333343 (2009).

Kroemer G, Reed JC: Mitochondrial control of cell death. Nat Med 6:513-519 (2000).

Lammer EJ, Cordero JF, Khoury MJ: Exogenous sex hormone exposure and the risk for VACTERL association. Teratology 34:165-169 (1986).

Lemasters JJ, Qian T, Bradham CA, Brenner DA, Cascio WE, et al: Mitochondrial dysfunction in the pathogenesis of necrotic and apoptotic cell death. J Bioenerg Biomembr 31:305-319 (1999).

Levine F, Muenke M: VACTERL association with high prenatal lead exposure: similarities to animal models of lead teratogenicity. Pediatrics 87:390-392 (1991).

Li K, Li Y, Shelton JM, Richardson JA, Spencer E, et al: Cytochrome c deficiency causes embryonic lethality and attenuates stress-induced apoptosis. Cell 101:389-399 (2000).

Loffredo CA, Wilson PD, Ferencz C: Maternal diabetes: an independent risk factor for major cardiovascular malformations with increased mortality of affected infants. Teratology 64:98-106 (2001)

- Mardach R, Verity MA, Cederbaum SD: Clinical, pathological, and biochemical studies in a patient with propionic acidemia and fatal cardiomyopathy. Mol Genet Metab 85:286290 (2005).

-Marx J, Pretorius E, Bornman MS: The neurotoxic effects of prenatal cardiac glycoside exposure: a hypothesis. Neurotoxicol Teratol 28:135-143 (2006).

Massoud AF, Leonard JV: Cardiomyopathy in propionic acidaemia. Eur J Pediatr 152:441445 (1993).

Merlob P, Naor N: Drug induced VATER association: is dibenzepin a possible cause? J Med Genet 31:423 (1994)

Nissenkorn A, Michelson M, Ben-Zeev B, Lerman-Sagie T: Inborn errors of metabolism: a cause of abnormal brain development. Neurology 22:56:1265-1272 (2001). 
Nora AH, Nora JJ: A syndrome of multiple congenital anomalies associated with teratogenic exposure. Arch Environ Health 30:17-21 (1975).

Nora JJ, Nora AH, Blu J, Ingram J, Fountain A, Peterson M: Exogenous progestogen and estrogen implicated in birth defects. JAMA 240:837-843 (1978).

-Okun JG, Hörster F, Farkas LM, Feyh P, Hinz A, et al: Neurodegeneration in methylmalonic aciduria involves inhibition of complex II and the tricarboxylic acid cycle, and synergistically acting excitotoxicity. J Biol Chem 277:14674-14680 (2002).

Ornoy A: Embryonic oxidative stress as a mechanism of teratogenesis with special emphasis on diabetic embryopathy. Reprod Toxicol 24: 31-41 (2007).

- Ornoy A, Rand SB, Bischitz N: Hyperglycemia and hypoxia are interrelated in their teratogenic mechanism: studies on cultured rat embryos. Birth Defects Res B Dev Reprod Toxicol 89:106-115 (2010).

- Prince J, Jia S, Båve U, Annerén G, Oreland L: Mitochondrial enzyme deficiencies in Down's syndrome. J Neural Transm Park Dis Dement Sect 8:171-181 (1994).

Quan L, Smith DW: The VATER association: vertebral defects, anal atresia, tracheoesophageal fistula with esophageal atresia, radial dysplasia. Birth Defects Orig Art Ser 8:75-78 (1972).

Quan L, Smith DW: The VATER association. Vertebral defects, Anal atresia, T-E fistula with esophageal atresia, Radial and Renal dysplasia: a spectrum of associated defects. J Pediatr 82:104-107 (1973).

-Rittler M, Paz JE, Castilla EE: VACTERL association, epidemiologic definition and delineation. Am J Med Genet 63:529-536 (1996).

- Roat E, Prada N, Ferraresi R, Giovenzana C, Nasi $\mathrm{M}$, et al: Mitochondrial alterations and tendency to apoptosis in peripheral blood cells from children with Down syndrome. FEBS Lett 581:521-525 (2007).

Rudolph C, Rudolph A, Hostetter M, Lister G, Siegel N: Rudolph's Pediatrics, ed 21 (McGraw-Hill Professional, New York 2002).

-Saijo H, Tanaka H, Ito J, Tasaki T, Cho K, et al: Pyruvate dehydrogenase complex deficiency with multiple minor anomalies. Acta Paediatr Jpn 39:230-232 (1997).

- Schaefer AM, McFarland R, Blakely EL, He L, Whittaker RG, et al: Prevalence of mitochondrial DNA disease in adults. Ann Neurol 63:35-39 (2008).

-Schuchmann S, Heinemann U: Increased mitochondrial superoxide generation in neurons from trisomy 16 mice: a model of Down's syndrome. Free Radic Biol Med 28:235-250 (2000).

-Schwab MA, Sauer SW, Okun JG, Nijtmans LG, Rodenburg RJ, et al: Secondary mitochondrial dysfunction in propionic aciduria: a pathogenic role for endogenous mitochondrial toxins. Biochem J 398:107-112 (2006).
Schwartz M, Vissing J: Paternal inheritance of mitochondrial DNA. N Engl J Med 347:576580 (2002).

Scriver CR, Beaudet A, Sly ES, Valle D, Childs B, et al: The Metabolic and Molecular Bases of Inherited Disease, ed 8. (McGraw-Hill Professional, New York 2001)

- Seo J, Kim do Y, Kim AR, Kim DY, Kim SC, et al: An 18-year experience of tracheoesophageal fistula and esophageal atresia. Korean J Pediatr 53:705-710 (2010).

Shao J, White CC, Dabrowski MJ, Kavanagh TJ, Eckert ML, Gallagher EP: The role of mitochondrial and oxidative injury in BDE 47 toxicity to human fetal liver hematopoietic stem cells. Toxicol Sci 101:81-90 (2008).

Shih VE, Mandell R: Fumarate Hydratase Deficiency, in Pagon RA, Bird TD, Dolan CR, Stephens K, Adam MP (eds): GeneReviews [Internet] (University of Washington, Seattle 2006). http://www.ncbi.nlm.nih.gov/books/ NBK1506/.

Skladal D, Halliday J, Thorburn DR: Minimum birth prevalence of mitochondrial respiratory chain disorders in children. Brain 126: 1905-1912 (2003).

-Solomon BD: VACTERL/VATER Association. Orphanet J Rare Dis 6:56 (2011).

Solomon BD, Bous SM, Bianconi S, Pineda-Alvarez DE: Consideration of VACTERL association in patients with trisomy 21. Clin Dysmorphol 19:209-211 (2010a).

Solomon BD, Pineda-Alvarez DE, Raam MS, Bous SM, Keaton AA, et al: Analysis of component findings in 79 patients diagnosed with VACTERL association. Am J Med Genet A 152A:2236-2244 (2010b).

-Solomon BD, Pineda-Alvarez DE, Raam MS, Cummings DA: Evidence for inheritance in patients with VACTERL association. Hum Genet 127:731-733 (2010c).

Solomon BD, Patel A, Cheung SW, Pineda-Alvarez DE: VACTERL association and mitochondrial dysfunction. Birth Defects Res A Clin Mol Teratol 91:192-194 (2011).

-Sperl W, Jesina P, Zeman J, Mayr JA, Demeirleir $L$, et al: Deficiency of mitochondrial ATP synthase of nuclear genetic origin. Neuromuscul Disord 12:821-829 (2006).

-Spinazzola A: Mitochondrial DNA mutations and depletion in pediatric medicine. Semin Fetal Neonatal Med 16:190-196 (2011).

Stone DL, Biesecker LG: Mitochondrial NP 3243 point mutation is not a common cause of VACTERL association. Am J Med Genet 72: 237-238 (1997).

Temtamy SA, Miller JD: Extending the scope of the VATER association: definition of the VATER syndrome. J Pediatr 85:345-349 (1974).

-Thauvin-Robinet C, Faivre L, Huet F, Journeau P, Glorion C, et al: Another observation with VATER association and a complex IV respiratory chain deficiency. Eur J Med Genet 49: 71-77 (2006)

Thorburn DR, Dahl HM: Mitochondrial disorders: genetics, counseling, prenatal diagno- sis and reproductive options. Am J Med Genet 106:102-114 (2001).

-Tiano L, Busciglio J: Mitochondrial dysfunction and Down's syndrome: is there a role for coenzyme Q(10)? Biofactors 37:386-392 (2011).

- Tüzel E, Samli H, Kuru I, Türkmen S, Demir Y, et al: Association of hypospadias with hypoplastic synpolydactyly and role of $\mathrm{HOXD13}$ gene mutations. Urology 70:161-164 (2007).

-Van Blerkom J: Mitochondria in early mammalian development. Semin Cell Dev Biol 20: 354-64 (2009).

van Rooij IA, Wijers CH, Rieu PN, Hendriks HS, Brouwers MM, et al: Maternal and paternal risk factors for anorectal malformations: a Dutch case-control study. Birth Defects Res A Clin Mol Teratol 88:152-158 (2010).

Voet D, Voet JG, Pratt CW: Fundamentals of Biochemistry, ed 2. (John Wiley and Sons, Inc., Hoboken 2006).

von Kleist-Retzow JC, Cormier-Daire V, Viot G, Goldenberg A, Mardach B, et al: Antenatal manifestations of mitochondrial respiratory chain deficiency. J Pediatr 143:208-212 (2003).

-Wajner M, Goodman SI: Disruption of mitochondrial homeostasis in organic acidurias: insights from human and animal studies. J Bioenerg Biomembr 43:31-38 (2011).

-Wallace DC: Mouse models for mitochondrial disease. Am J Med Genet 106:71-93 (2001).

Wang YY, Sui KX, Li H, Ma HY: The effects of lead exposure on placental NF-kappaB expression and the consequences for gestation. Reprod Toxicol 27:190-195 (2009).

-Wang Q, Moley KH: Maternal diabetes and oocyte quality. Mitochondrion 10:403-410 (2010).

-Weaver DD, Mapstone CL, Yu PL: The VATER association. Analysis of 46 patients. Am J Dis Child 140:225-229 (1986).

-White SL, Collins VR, Wolfe R, Cleary MA, Shanske S, et al: Genetic counseling and prenatal diagnosis for the mitochondrial DNA mutations at nucleotide 8993. Am J Hum Genet 65:447-482 (1999).

-Wijers $\mathrm{CH}$, de Blaauw I, Marcelis CL, Wijnen $\mathrm{RM}$, Brunner $\mathrm{H}$, et al: Research perspectives in the etiology of congenital anorectal malformations using data of the International Consortium on Anorectal Malformations: evidence for risk factors across different populations. Pediatr Surg Int 26:1093-1099 (2010).

Wortmann SB, Rodenburg RJ, Jonckheere A, de Vries MC, Huizing M, et al: Biochemical and genetic analysis of 3-methylglutaconic aciduria type IV: a diagnostic strategy. Brain 132: 136-146 (2009).

-Yanicostas C, Soussi-Yanicostas N, El-Khoury R, Bénit P, Rustin P: Developmental aspects of respiratory chain from fetus to infancy. Semin Fetal Neonatal Med 16:175-180 (2011).

Zhao X, Sun M, Zhao J, Leyva JA, Zhu H, et al: Mutations in HOXD13 underlie syndactyly type $\mathrm{V}$ and a novel brachydactyly-syndactyly syndrome. Am J Hum Genet 80:361-371 (2007). 